\title{
Industrial specialization - the most important factor for sustainable development and the region economic security
}

\author{
Natalya Novikova*, and Elena Strogonova \\ Ural State University of Economics, 8 Marta Str., 62,620144 Ekaterinburg, Russia
}

\begin{abstract}
In article the authors argue that the industrial future is the most important factor in ensuring sustainable development of a traditional industrial region. The conclusions are based on the study of the first results of socio-economic development in the context of the coronavirus pandemic, a prominent representative of traditionally industrial regions the Sverdlovsk region. The authors base their own research on the conceptual guidelines of the scientific paradigm of sustainable development. Operative statistical data on the Sverdlovsk region are presented. In the study the conclusions were reached about the immediate prospects for the development of the Sverdlovsk region economy in the context of a new coronavirus infection. The processes that are an approximate scenario for the development of events at the regional level were identified. The importance of maintaining industrial specialization in the new realities of the economy as an important factor in sustainable development not only at the national level, but also at the regional level was revealed.
\end{abstract}

\section{Introduction}

During many years, the environment has been perceived as external to humans, necessary for use and exploitation, assessed from the standpoint of complete enslavement by the interests of industrial production. The prevailing view in many economies around the world is that international prosperity and human well-being can be achieved through the expansion of global trade and industry[1]. The system of government is undergoing significant changes in the context of global trends associated with the pandemic. Currently the providing sustainable to economic processes requires action, first of all, from the state, and only then from private enterprise.

\section{Materials and Methods}

The concept of sustainable region development is currently at the formative stage. The different approaches and theories of sustainable development are identified, the spatial

\footnotetext{
*Corresponding author: novikova@usue.ru
} 
model of conceptual concepts «sustainable development» is developed [2]. Let us turn to the origins. Ushakova's dictionary of the Russian language the concept of «sustainable» is understood as, first, having the property of standing firmly, not falling, not hesitating; able to maintain this state, despite the actions of various forces (for example, stable balance); secondly, not amenable, not subject to fluctuations and changes (stable currency); thirdly, solid, persistent, reliable, not amenable to influences [3].

During the second half of the XX century with the help of various mathematical models, scientists tried to prove that the growth in production and growth in consumption have a huge number of negative consequences, including the death of humanity. The most famous model belonged to Jay Forrester. The results of his research were published in 1971 and showed that an increase in production in 50 years will lead to a decrease in the quality of life of people [4].

At the same time as Jay Forrester's research, a global threat assessment was carried out by a team of scientists led by Dennis Meadows. The researchers analyzed the main factors of economic growth and showed the development scenarios of mankind in conditions of resources depletion. The developed scenarios contained, in addition to pessimistic forecasts, a set of optimal or sustainable development scenarios, which gave impetus to the terminology formation [5].

There is a problem in the practical application of the concept of sustainability - ideas are interpreted differently in different countries and regions of the world and, therefore, are translated into different ways in national policies. These national approaches to developing the line of power are based on different scientific theories. As a result, ideas of sustainability in the socio-economic sphere are increasingly becoming an area of political controversy. Systematization and clear positioning of various sustainable development theories is essential to provide a reliable tool to aid in decision-making [6].

Each region of the world has its own benchmarks applied to regional economic systems. The list of benchmarks is thought out in accordance with the requirements of the region's economy and is defined in such a way as to create conditions for sustainable economic development in the long term. Under normal conditions, the region is capable of stable and even development. This development is associated with interaction with the geopolitical center. The variability of socio-economic factors carries with it damage from external influences [7].To eliminate such opportunities, the security of the system must be ensuring. But, unfortunately, not everything depends on economic monitoring.

An enormous contribution to the development of the problem was made by the economist-mathematician V.V. Novozhilov [8]. A study of all possible aspects of regional socio-economic systems and their translation into a sustainable development model can be found in the works of A.G. Granberg [9], A.I. Tatarkina [10], T.V. Uskova [11] and etc.

The concept of sustainability of socio-economic development should be considered systematically, since the interpretation of this term only from the economic, social or environmental side is not able to reflect all aspects. Further under the stable (sustainable) socio-economic development of the region, we will mean development that allows negative and zero values of economic growth rates, but over a period of time has a positive direction [12].

For many years and in different eras, scientists say that we are living at a turning point, in an extremely important, essentially new era in the life of mankind, its history on our planet [13]. 


\section{Results and Discussion}

The coronavirus pandemic was a serious test of the sustainability and economic security of the regional socio-economic system. Prove what has been said according to the data of the socio-economic development of the Sverdlovsk region.

The coronavirus pandemic has a tremendous impact on the global economy and the economy of Russia as a whole.

The Sverdlovsk region found itself in a new economic reality. Note that today it is possible to give only preliminary estimates of the ongoing economic changes. The reason is quite simple - there are few accumulated official statistical observations in the country as a whole and in its regions.

To assess the situation, the operational statistics for January-June 2020 are used. Their comparison with the same period in 2019 allows to draw the first cautious conclusions.

Our analysis allows to assert that the «genetic code» of the Sverdlovsk region, which has been formed over more than three centuries, namely the industrial specialization of the economy, has created a so-called «airbag» thanks to which the region was able to withstand global challenges.

The Sverdlovsk region, like other regions of the Urals, is characterized by a special structure of the economy, in which the industries of specialization are the manufacturing industry, with a high share of the military-industrial complex, metallurgical production, mechanical engineering with the dominance of large enterprises.

Large manufacturing enterprises of the Sverdlovsk region were able to withstand the pandemic. The backbone enterprises practically did not stop their work.

Our arguments are confirmed by the data in the table and figure, which show the dynamics of the main economic indicators of the Sverdlovsk region for January-June 2020, calculated as $\%$ of the corresponding month of 2019 . We used the operational statistical indicators of Russian Federal State Statistics Service for the Sverdlovsk Region and the Kurgan Region.

In table 1, the indicators are highlighted in color, which have decreased compared to 2019 .

Table 1. Dynamics of the main economic indicators of the Sverdlovsk region in January-June 2020, in $\%$ to the corresponding month of 2019

\begin{tabular}{|l|l|l|l|l|l|l|}
\hline \multicolumn{1}{|c|}{ Indicators } & January & February & March & April & May & June \\
\hline Industrial production index & 101,8 & 114,5 & 100,1 & 108,2 & 97,1 & 102,3 \\
\hline $\begin{array}{l}\text { Production index by type of } \\
\text { activity «Mining» }\end{array}$ & 99,6 & 106,6 & 102,2 & 102,0 & 101,8 & 100,4 \\
\hline $\begin{array}{l}\text { Production index by type of } \\
\text { activity «Manufacturing } \\
\text { industries» }\end{array}$ & 105,0 & 117,6 & 100,9 & 109,8 & 95,9 & 102,8 \\
\hline $\begin{array}{l}\text { Production index by type of } \\
\text { activity «Electricity, gas } \\
\text { and steam supply; air } \\
\text { conditioning» }\end{array}$ & 88,1 & 102,4 & 99,6 & 112,1 & 110,7 & 102,0 \\
\hline $\begin{array}{l}\text { The index of the physical } \\
\text { volume of work performed } \\
\text { by the type of activity } \\
\text { «Construction» }\end{array}$ & 123,7 & 104,0 & 89,8 & 104,1 & 100,0 & 97,0 \\
\hline $\begin{array}{l}\text { Commissioning of } \\
\text { residential buildings }\end{array}$ & 145,5 & 84,3 & 105,9 & 88,1 & 74,7 & 94,8 \\
\hline $\begin{array}{l}\text { Transportation of goods by } \\
\text { road of organizations }\end{array}$ & 105,1 & 111,5 & 110,2 & 99,8 & 103,1 & 100,0 \\
\hline & & & & & &
\end{tabular}


Table 1. Continued

\begin{tabular}{|l|l|l|l|l|l|l|}
\multicolumn{1}{|c|}{ Indicators } & January & February & March & April & May & June \\
\hline $\begin{array}{l}\text { Retail trade turnover (in } \\
\text { comparable prices) }\end{array}$ & 101,2 & 103,4 & 103,1 & 84,2 & 83,7 & 87,4 \\
\hline $\begin{array}{l}\text { Food retail trade turnover } \\
\text { (in comparable prices) }\end{array}$ & 102,5 & 103,4 & 101,7 & 92,2 & 91,9 & 92,6 \\
\hline $\begin{array}{l}\text { Non-food retail trade } \\
\text { turnover (in comparable } \\
\text { prices) }\end{array}$ & 100,1 & 103,4 & 104,5 & 76,4 & 75,7 & 82,4 \\
\hline $\begin{array}{l}\text { The volume of paid services } \\
\text { to the public (in comparable } \\
\text { prices) }\end{array}$ & 103,3 & 101,1 & 100,5 & 54,9 & 56,9 & 52,3 \\
\hline $\begin{array}{l}\text { The number of employed in } \\
\text { the regional economy, } \\
\text { thousand pers. }\end{array}$ & 2069,4 & 2025,3 & 1996,9 & 1963,6 & 1967,5 & 1978,4 \\
\hline $\begin{array}{l}\text { Number of unemployed, } \\
\text { thousand pers. }\end{array}$ & 86,4 & 90,6 & 95,1 & 114,3 & 137,7 & 144,3 \\
\hline
\end{tabular}

*Note: The table was compiled according to information for monitoring the socio-economic situation of the Sverdlovsk region for 2020, https://sverdl.gks.ru/folder/33988

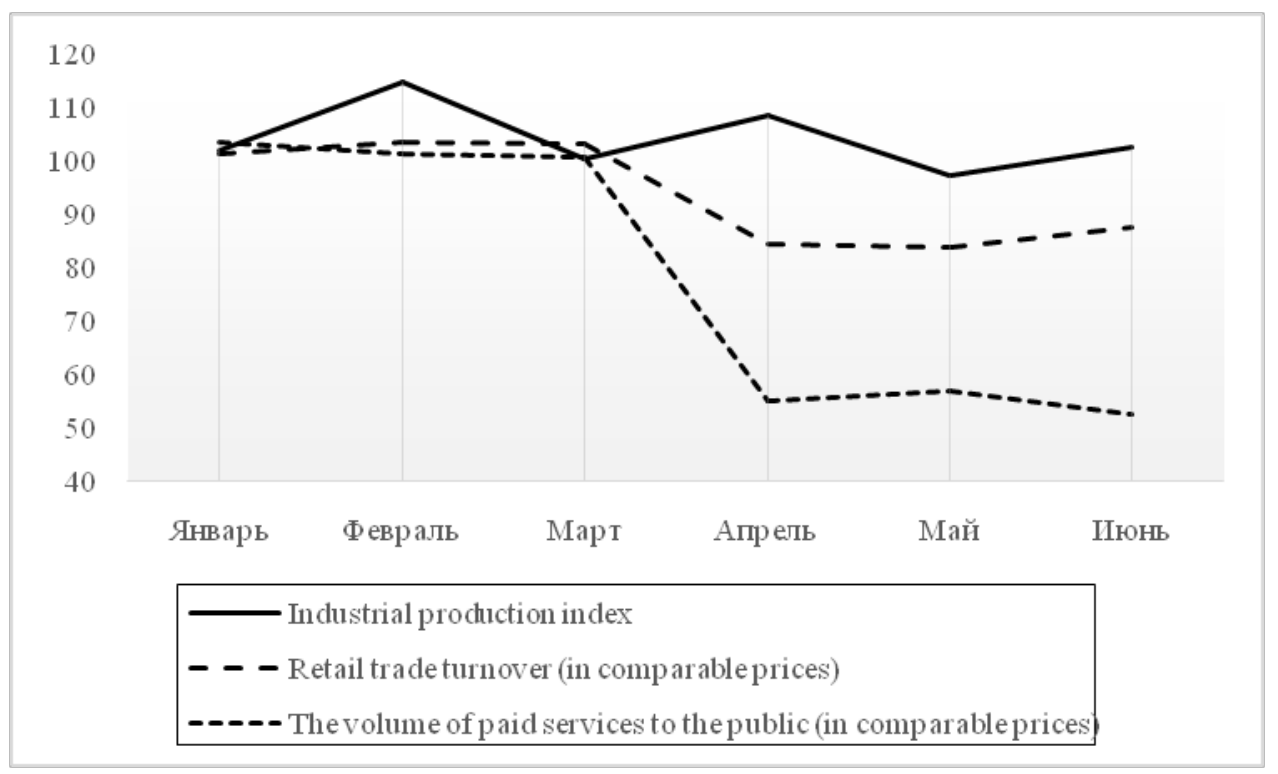

Fig. 1. Dynamics of economic indicators of the Sverdlovsk region in January-June 2020, in $\%$ to the corresponding month of 2019

The continued stability of the industry of the Sverdlovsk region is shown by the following: in 2020, the industrial production index was 3\% lower than the same indicator in 2019 only in May, the data for April and June 2020 showed growth.

The industrial production index in the Sverdlovsk region, according to the Russian Federal State Statistics Service for the Sverdlovsk Region and Kurgan Region, in JanuaryJune 2020 amounted to $103.8 \%$ compared to the same period in 2019 .

In the leading branch of the region - metallurgical production - it amounted to $101.7 \%$. 
However, not all sectors of the region's economy turned out to be equally stable in the new economic reality. In particular, retail trade turnover in comparable prices for AprilJune 2020 decreased by $15-16 \%$ compared to 2019 . The drop was especially noticeable in the segment of non-food products trade, where the drop was more than $20 \%$.

The sector of providing paid services to the public found itself in an even more difficult situation. The volume of provision of paid services to the public in April-June 2020 almost halved compared to 2019 .

In our view, the main factors of this situation were: firstly, the activities suspension of a number of organizations in the retail trade and the service sector in connection with the measures introduced to overcome the spread of coronavirus infection; secondly, the drop in incomes of the region public; thirdly, a change in consumer preferences, an orientation towards a cheaper segment of goods, a search for substitute goods.

The indicator of a noticeable increase in the number of unemployed in the region is alarming. So, in April 2020, the number of unemployed increased by 19.2 thousand pers. compared to March. and reached 114.3 thousand pers. The growth continued in May 2020, another 23.4 thousand pers. were added when the number of unemployed reaches 137.7 thousand pers.

The number of unemployed is an important indicator of the state of the region's economy. So, according to the Ministry of Economy and Territorial Development of the Sverdlovsk Region, the number of unemployed officially registered with the employment service as of July 1, 2020 amounted to 90,705 people (as of July 1, 2019 - 25,118 people). The level of registered unemployment on July 1, 2020 was 4.28\% (on July 1, 2019 $-1.17 \%)$.

The key factors in the growth of the unemployed number in the Sverdlovsk region are the following: first, the deterioration of the economic situation in the region, which caused a decrease in economic activity, a decrease in the number of employed. Employers are actively looking for ways to optimize costs, with a reduction in the number of employees coming to the fore; secondly, the growth of applications to employment centers of persons who were arranged unofficially, but in a pandemic were unemployed, but were entitled to social benefits.

What are the prospects for a change in the economic situation in the Sverdlovsk region under the influence of the coronavirus pandemic?

Early as March 2020, a team of scientists from the Ural State Economic University prepared an analytical note «Forecast of the development of the socio-economic situation in the Sverdlovsk region in the context of the spread of coronavirus infection». Many conclusions of scientists have been confirmed to date. Here are the main arguments for identifying prospects.

The current socio-economic situation in the Sverdlovsk region is determined by:

1. The general economic situation in the Russian Federation caused by the spread of a new coronavirus infection in the world, which provoked the phenomenon of the global economic crisis, characterized by a fall in commodity and financial markets.

2. A set of measures to prevent the spread of coronavirus infection, implemented at all levels of government, in institutions, organizations and enterprises in all spheres of social, economic and economic life of the Russian Federation.

The phenomena of the global economic crisis that have (in fact) the most significant impact on the socio-economic development of the Sverdlovsk region:

1. Fluctuations in demand in commodity markets, primarily in the markets of ferrous and non-ferrous metals.

2. Devaluation of the national currency and acceleration of inflation, and reduced access to financial and banking services.

3. Capital outflow and decrease in investment activity. 
4. Drawdown of the functioning and development of small and medium-sized businesses, especially enterprises of the consumer sector and the service sector.

5. Clenching all segments of the tourism industry: all categories of consumers - from children to business tourism, hotel and restaurant business and carriers.

6. Deterioration of the situation in the sector of households, which are the most important economic agents.

As a result of these phenomena, in the near future, the state of the economy of the Sverdlovsk region (probably) will be characterized by the following processes.

1. Decrease in the growth rate of the gross regional product. Deterioration of the financial and economic situation of industrial enterprises and organizations, obliging to switch to a policy of saving money on labor costs and freezing investment programs that require financing of «long» assets. In these conditions, a reduction in the taxable base for taxes received by the budgets of all levels may acquire the character of a stable trend in the medium term.

2. Elimination of a number of manufacturing enterprises, primarily small and medium-sized ones, which will predetermine a decrease in the production of products (works, services) of local producers, as well as the release of workers, which form the growth of the phenomenon of the most socially dangerous unemployment - cyclical.

3. Gradual decline in the standard of living of the working-age public. The first stage is a moderate decline in living standards, since constraining factors will work, which will be employers' expectations of a quick improvement in the economic situation and, possibly, some regulatory actions of the Government. At this stage (in conditions of restraining the processes of layoffs), labor costs will decrease at a rate lower than the rate of decline in production volumes, which will, among other things, be characterized by a significant drop in labor productivity. After it becomes obvious to the mass employer that the normal (at a certain level) functioning of the business is impeded by the discrepancy between labor costs and the final result, the process of laying off workers will accelerate and, accordingly, the second stage will begin - an accelerated decline in the standard of living of the able-bodied the public.

4. The decrease in the effective demand of the public (a stimulating factor in the development of the economy under normal conditions) is the result of the combined action of a number of conditions emerging in the current time: falling incomes of the population, accelerating inflation rates, increasing propensity of certain categories of citizens to save, tightening requirements of banks to the financial condition of ordinary borrowers.

5. Falling revenues of regional and local budgets with a simultaneous change in the structure of federal budget expenditures in favor of solving urgent social problems and tasks (but at the expense of financing priority national projects, which, in the long term, will obviously have a negative impact on the rate of economic growth).

\section{Conclusion}

Sustainable development is a «young term». But in the scientific community, this term is used widely, in connection with the recent active manifestations of negative processes that affect the presence of Man on planet Earth. The above processes are a likely consequence of the observed manifestations of global economic and financial crises, the development of which should be considered from the standpoint of the specifics of the situation with coronavirus infection, without eliminating which it is not possible to overcome crises. In order to overcome problems at the regional level, a clear understanding of the approach to defining sustainable development is necessary, which will provide the power structures of the national and regional levels with an acceptable tool for making managerial decisions to a number of problems and a real overcoming of the crisis in the country as a whole. Using 
the concept of sustainable development, it is possible to determine the prospects for economic dynamics and strengthening economic security.

\section{References}

1. D. Reid, Sustainable development: an introductory guide (1995)

2. J.A. Mingaleva, Vestnik Mosk. University, 6 (6) (2017)

3. D.N. Ushakov, The Big Explanatory Dictionary of the Modern Russian Language (2008)

4. J. W. Forrester, World Dynamics (1971)

5. D. L. Meadows, D. H. Meadows, J. Randers, W. W. Behrens, The Limits to Growth: A Report for the Club of Rome's Project on the Predicament of Mankind (1972)

6. A. Blowers, The Time for Change. In Planning for a Sustainable Environment, Blowers (1993)

7. E. S. Bordyashov, Russian Entrepreneurship, 8 (2007)

8. V.V. Novozhilov, At the origins of true economic science (1995)

9. A.G. Granberg, V.I. Suslov, S.A. Suspitsyn. Region: economics and sociology, 2 (2008)

10. A. I. Tatarkin, D. S. Lvov, A. A. Kuklin, A. L. Myzin, L. L. Bogatyrev, B. A. Korobitsyn, V. I. Yakovlev, Modeling sustainable development as a condition for increasing the economic security of the territory (1999)

11. T.V. Uskova, Management of sustainable development of the region (2009)

12. H. Bossel, Indicators of sustainable development: theory, method, practical use (2001)

13. V. I. Vernadsky, Scientific thought as a planetary phenomenon (1991) 